\title{
Generation of Reactive Ketenes under Flow Conditions through Zinc-Mediated Dehalogenation
}

\author{
Andreas Hafner \\ Steven V. Ley* \\ Department of Chemistry, University of Cambridge, \\ Lensfield Road, Cambridge, CB2 1EW, UK \\ svl1000@cam.ac.uk \\ Dedicated to Peter Vollhardt, dear friend and \\ academic founder of Synlett.
}

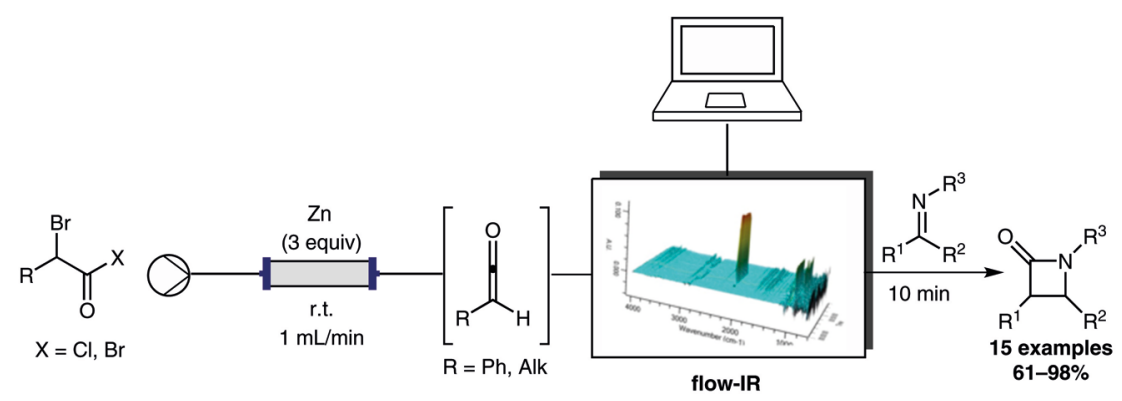

Received: 18.02.2015

Accepted after revision: 03.04.2015

Published online: 03.06 .2015

DOI: 10.1055/s-0034-1380679; Art ID: st-2015-b0113-I

License terms: (C) (P)

Abstract Herein, we describe the generation of highly reactive monoalkyl and phenyl ketenes by using a dehalogenation procedure under flow conditions. All ketenes were generated in good yields (determined by quenching with an appropriate aniline derivative) and showed high reactivity in the [2+2] cycloaddition with imines, resulting in the formation of a range of $\beta$-lactams at room temperature in less than 10 minutes. Furthermore, initial experiments were performed by using these reactive ketenes for the synthesis of $\beta$-lactams under flow conditions.

Keywords ketenes, reactive intermediates, lactams, flow chemistry, cycloaddition

The generation and control of reactive/unstable intermediates is a fundamental part of organic chemistry because it allows the synthesis of unique molecular structures. Reactions with reactive intermediates are sometimes challenging as they are difficult to isolate, show only moderate selectivity or tend to dimerise or polymerise under the reaction conditions used for their generation in a classical batch-mode environment.

Ketenes are versatile compounds because they possess unique chemical properties and reactivity. ${ }^{1}$ They can take part in various [2+2] cycloaddition reactions, giving direct access to interesting structural motifs. Most importantly, the reaction of ketenes with imines offers a straightforward route to biological interesting $\beta$-lactams, which are an important structural motif in medicinal chemistry. ${ }^{2}$

Whereas secondary ketenes can be synthesised and isolated relatively easily, ${ }^{3}$ most primary ketenes are highly reactive and their synthesis and isolation is difficult. Therefore, the method of choice for reactions with these reactive ketenes is their generation in situ, starting from the corresponding acyl chloride in the presence of a tertiary amine base and an appropriate coupling partner. ${ }^{4}$ However, the presence of Lewis bases, for example tertiary amines, can alter or inhibit certain reaction pathways of ketenes. ${ }^{5}$ Therefore, in an effort to discover new pathways involving reactive intermediates, we began investigations into the base-free generation of ketenes.

An alternative, base-free route to reactive ketenes was reported by Staudinger around 100 years ago. ${ }^{6}$ He demonstrated that reactive ketenes can be obtained by a zinc-mediated dehalogenation procedure starting from $\alpha$-bromo acyl bromides. However, the yields obtained by this method under batch-mode conditions were very low because of side reactions such as polymerisation. To prevent the generated ketenes from undergoing dimerisation or polymerisation, this method was improved by Ward et al. ${ }^{7}$ By direct co-distillation of the generated ketene together with tetrahydrofuran (THF) from the reaction flask it was possible to significantly improve the yield of obtained ketene. However, immediate cooling of the collecting flask with liquid nitrogen was necessary because the authors noted that the generated ketenes tend to dimerise or polymerise even at $-80{ }^{\circ} \mathrm{C}$.

By using this dehalogenation procedure as a starting point, we assumed that side reactions such as dimerisation and polymerisation could be decreased or even inhibited by using flow chemistry as a tool to control the generation of reactive intermediates directly. Previously, we could demonstrate that relatively unstable benzylic diazo compounds are accessible by oxidation of readily available benzyl hydrazones with $\mathrm{MnO}_{2}$ through translocation. ${ }^{8}$ Here, we describe the controlled in-flow generation of reactive mono-alkyl and mono-phenyl ketenes and their usage in the $[2+2]$ Staudinger reaction with imines. It should be not- 


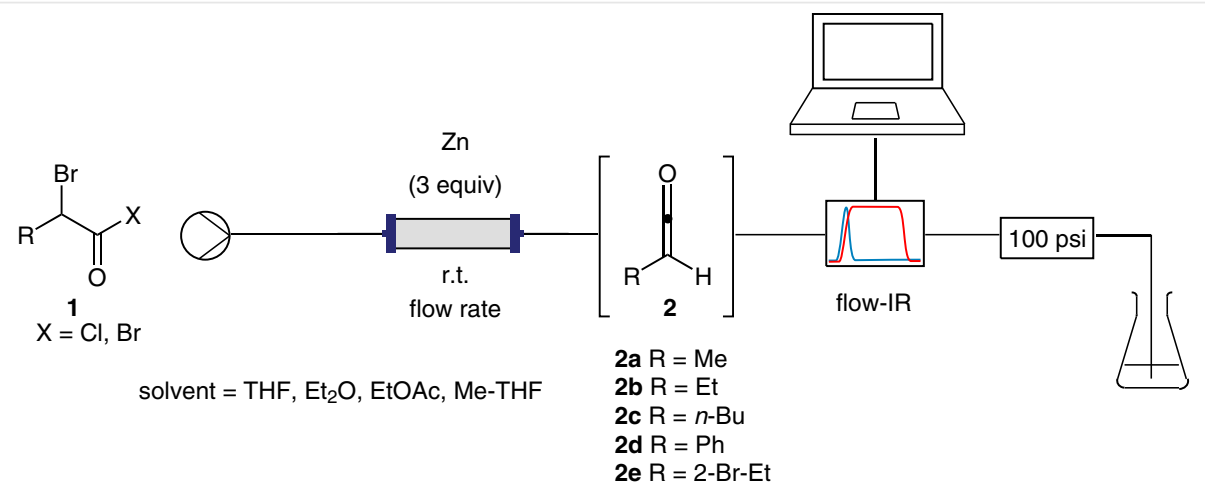

Scheme 1 General setup for the generation of reactive ketenes starting from $\alpha$-brominated acyl halides (1). The stream of reactive ketene was directly quenched with an appropriate coupling partner.

ed that the Lectka group has previously reported a different flow approach towards the generation of ketenes based on a polymer-supported base. . $\mathrm{b}, \mathrm{c}^{\mathrm{s}}$

In contrast to classical batch-mode chemistry, for which all reaction partners must be present in one chemical environment, flow chemistry allows the synthesis of complex molecules by translocation of an intermediate from one chemical environment into another without the need for isolation. ${ }^{9}$ This advantage of flow chemistry is especially useful when applied in the generation of reactive intermediates. Whereas it is difficult to control the reactivity of a reactive species in batch mode, flow chemistry offers various parameters (flow rate, retention time, temperature, inline analysis etc.) to give improved control over these intermediates. ${ }^{10}$ Therefore, it is (in contrast to batch-mode chemistry, for which these reactive species are mostly generated in situ in the presence of an appropriate coupling partner) possible to generate a reactive species specifically and then react it with another substrate.

By using Staudinger's dehalogenation procedure as inspiration, we explored the generation of reactive ketenes under flow conditions by using a simple Omnifit column loaded with zinc and a source of $\alpha$-bromoacyl bromides as ketene precursors. Notably, the application of metals in special cartridges for the preparation of zinc species under flow conditions has been reported previously. ${ }^{11}$

Ketenes can be easily monitored by their characteristic IR band at around $2100 \mathrm{~cm}^{-1}$. Thus, it seemed reasonable to use an in-line IR spectrometer as an analytical tool to determine and follow the formation of reactive ketenes. With $\alpha$ bromopropionyl bromide (1a) as a test substrate $(0.1 \mathrm{M}$ in $\mathrm{THF}$ ), we were pleased to see the corresponding ketene band $\left(2116 \mathrm{~cm}^{-1}\right)$ in the IR spectra when commercially available zinc dust was packed into an Omnifit column and a flow rate of $0.5 \mathrm{~mL} / \mathrm{min}$ was used (see Scheme 1 for the general setup). Unfortunately, the formation of the ketene was not stable and different runs showed different intensities of the ketene IR-band. This was mainly attributed to holes that were formed in the zinc column through genera- tion of readily soluble $\mathrm{ZnBr}_{2}$. However, this problem could be solved when zinc dust was activated by treatment with aq. $\mathrm{HCl}$ and mixed with commercially available glass beads. ${ }^{12}$

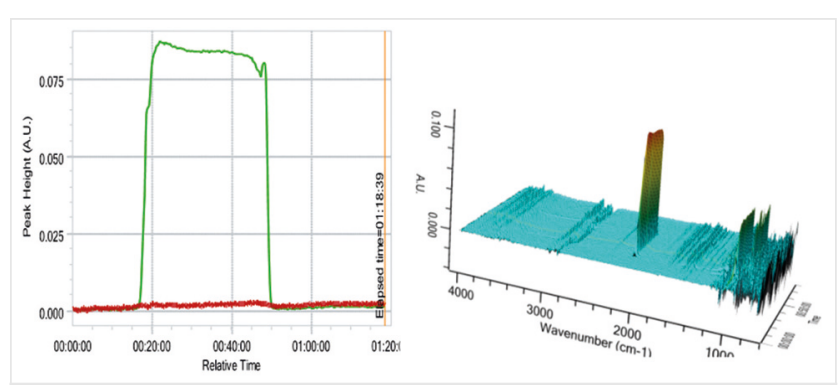

Figure 1 (Left) Intensity of the ketene band at $2107 \mathrm{~cm}^{-1}(0.1 \mathrm{M}$ in THF) of $n$-butyl ketene (2c, green) compared with starting material (red) using activated zinc ( $500 \mathrm{mg}$ ). Ketene formation was stable for 30 min. (Right) 3D spectra obtained by the in-line IR spectrometer of the ketene generation, showing clean conversion into the desired ketene.

Thus, an Omnifit column containing one third (3 equiv) activated zinc and two thirds glass beads $(<106 \mu \mathrm{m})$ allowed the stable generation of reactive monoalkyl ketenes at room temperature in THF. It should be noted that ketene formation was also possible in ethyl acetate, diethyl ether and methyltetrahydrofuran. Following the reaction by inline IR spectrometer allowed further control of ketene generation. Whereas more concentrated solutions $(0.2 \mathrm{M})$ of acyl bromide led to the occurrence of side products, optimal control could be achieved by using a $0.1 \mathrm{M}$ solution and a flow rate of $1.0 \mathrm{~mL} / \mathrm{min}$. In this case, ketene formation was quantitative and no side products could be observed in the IR spectra (Figure 1). We then attempted to quantify the yield of the ketene generated. This has been done previously by quenching the reactive ketene with a solution of an appropriate aniline derivative. ${ }^{6,7}$ Thus, the ketene solution (1.0 equiv in THF) was directly quenched with $p$-toluidine (1.5 equiv). By using highly reactive methyl ketene (2a) as test substrate, the corresponding amide could be obtained 
in $68 \%$ yield, without any 2 -bromo- $N$-( $p$-tolyl)propanamide as byproduct. This confirmed our in-line analysis, which showed clean conversion from the acyl bromide into the corresponding ketene.

With the optimised conditions in hand, we then started to explore the reactivity of these ketenes in the [2+2] cycloaddition reaction with imines to form $\beta$-lactams. Whereas the ketenes could be easily controlled under flow conditions, as shown by the in-line IR spectra, they readily polymerised after collecting the outcoming ketene stream in a flask. This result suggests that a coupling partner must be reasonably nucleophilic to react immediately with the highly reactive ketene.

Table 1 [2+2] Cycloaddition Reaction of Ketenes with Imines

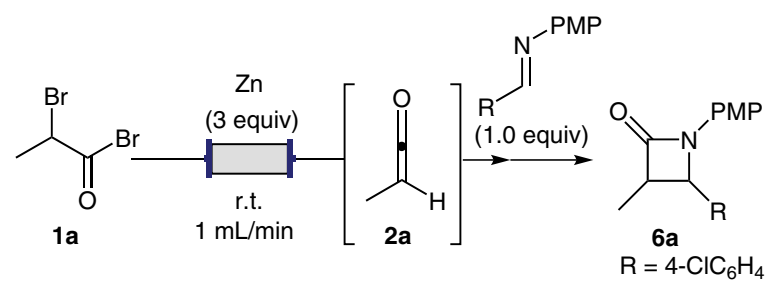

\begin{tabular}{lclll}
\hline Entry & Ketene (equiv) & Conc. (mol/L) & Solvent & Conversion (\%) $^{\mathrm{a}}$ \\
\hline 1 & 1.5 & 0.1 & $\mathrm{THF}$ & 40 \\
2 & 2.5 & 0.1 & $\mathrm{THF}$ & 45 \\
3 & 1.5 & 0.05 & $\mathrm{THF}$ & 51 \\
4 & 1.5 & 0.05 & $\mathrm{Et}_{2} \mathrm{O}$ & $98(91)^{\mathrm{b}}$ \\
\hline
\end{tabular}

a Conversion based on ${ }^{1} \mathrm{H}$ NMR analysis of the crude mixture after workup.

b Isolated yield after purification by column chromatography.

As shown in Table 1, first experiments using 1.5 equiv of a $0.1 \mathrm{M}$ solution of $1 \mathrm{a}$ in THF and (E)-1-(4-chlorophenyl)- $N$ (4-methoxyphenyl)methanimine as imine resulted in only moderate conversion into the desired $\beta$-lactam $\mathbf{6 a}$ (entry 1 ). However, yields could be improved by decreasing the ketene concentration to $0.05 \mathrm{M}$ (entry 3) and full conversion could be achieved by changing the solvent from THF to $\mathrm{Et}_{2} \mathrm{O}$ (entry 4). This could be explained by the higher Lewis acidity of $\mathrm{Zn}(\mathrm{II})$-salts in $\mathrm{Et}_{2} \mathrm{O}$, which further increases the electrophilicity of ketenes.

As shown in Scheme $2(\mathbf{6 a - f})$, methyl ketene reacts readily with a range of imines at room temperature to form the corresponding $\beta$-lactams in good to very good yields. The high reactivity was clear from the reaction time, since the reactions were complete in less than 10 minutes.

To demonstrate the generality of ketene formation, a range of other ketenes were generated under the same conditions. In all cases, the ketene IR band showed a similar intensity when monitored with an in-line IR spectrometer, suggesting similar generation of reactive ketene. The IR bands obtained in $\mathrm{Et}_{2} \mathrm{O}$ for the different ketenes were $2110 \mathrm{~cm}^{-1}$ (ethyl ketene, 2b), $2107 \mathrm{~cm}^{-1}$ ( $n$-butyl ketene,

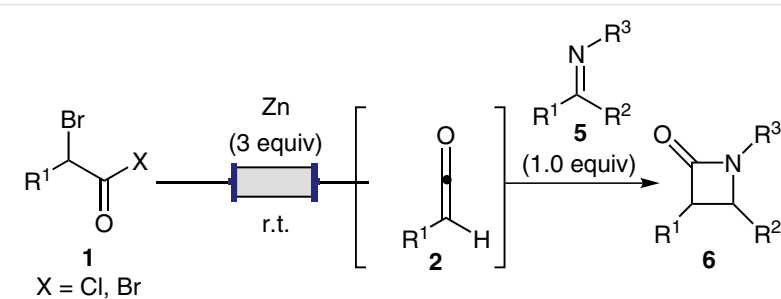

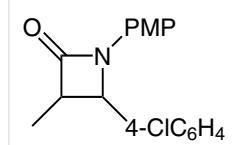

6a, $91 \%$ (cis/trans $=$ $1: 1.4$

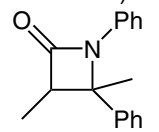

$6 e, 90 \%$ cis/trans = 1:1)

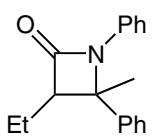

$6 \mathbf{i}, 84 \%$

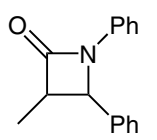

6b, $97 \%$

$($ cis/trans $=1: 4.7)($ cis/trans $=1.2: 1)$

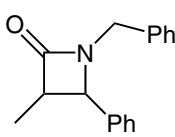

6c, $68 \%$

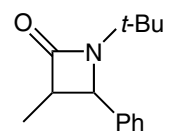

$6 \mathrm{~d}, 70 \%$ only cis

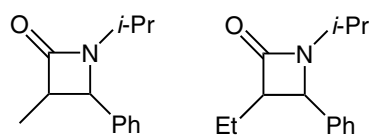

$6 \mathrm{~g}, 84 \%$

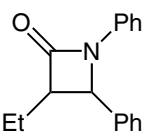

6h, $98 \%$

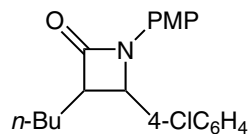

6j, $72 \%$

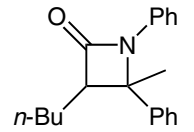

$6 k, 77 \%$
$($ cis/trans $=14.7: 1)($ cis/trans $=8.9: 1) \quad($ cis/trans $=1: 15.7)$

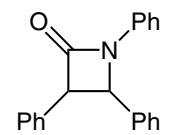

6I, $77 \%$
$($ cis/trans $=1: 1) \quad($ cis/trans $=1.2: 1) \quad($ cis/trans $=1: 1) \quad($ cis/trans $=1: 7.8)$

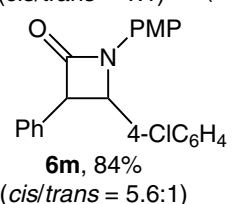
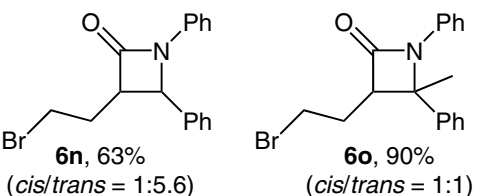

6o, $90 \%$ (cis/trans $=1: 1)$

Scheme 2 Reaction of imines with ketenes 2 generated in-flow. [a] Reaction conditions: A solution of $\alpha$-bromoacyl halide $\mathbf{1}(0.05 \mathrm{M})$ was pumped with a flow rate of $1.0 \mathrm{~mL} / \mathrm{min}$ through a Omnifit column containing $\mathrm{Zn}$ (3.0 equiv) and glass beads to generated the corresponding ketene 2 . The outcoming stream $(0.3 \mathrm{mmol})$ was directly reacted with the imine $\left(0.2 \mathrm{mmol}\right.$ dissolved in $\left.1 \mathrm{~mL} \mathrm{Et}{ }_{2} \mathrm{O}\right)$ at room temperature (addition over $6 \mathrm{~min}$, stirring for another $4 \mathrm{~min}$ ). Isolated yields after purification by column chromatography. ${ }^{[\mathrm{b}]}$ In case of 2-bromohexanoyl bromide $\mathbf{2 c}$, a flow rate of $0.5 \mathrm{~mL} / \mathrm{min}$ was used, under otherwise identical conditions.

2c), $2111 \mathrm{~cm}^{-1}$ (phenyl ketene, 2d) and $2118 \mathrm{~cm}^{-1}$ (2-bromoethyl ketene, 2e). All of these ketenes showed similar reactivity and selectivities compared to methyl ketene, and the reaction with imines resulted in similar good to very good yields (Scheme 2 ). As expected from the high reactivity of the ketenes, selectivity was relatively low in most cases. Whereas ketenimines $(\mathbf{6 e}, \mathbf{6 i}, \mathbf{6 k}$ and $\mathbf{6 0})$ always formed a 1:1 cis- and trans- $\beta$-lactam mixture, benzylideneaniline showed a preference for the trans over the cis form $(\mathbf{6 b}, \mathbf{6 h}$, $\mathbf{6 1}$ and 6n). In contrast to benzylideneaniline, benzylidenediisopropylamine (6f and $\mathbf{6 g}$ ) and benzylidene-tert-butylamine (6d) showed a higher tendency to form the cis product. These selectivities can be explained by the established mechanism of the Staudinger reaction ${ }^{13}$ and observations made by Moore et al. ${ }^{14}$ and by Xu et al. ${ }^{15}$ 
Notably, phenyl ketene 2d was prepared starting from the corresponding acyl chloride instead of the acyl bromide. While we found that the $\alpha$-bromo functionality was important for the smooth and stable generation of the corresponding ketene through zinc-mediated dehalogenation, both acyl chlorides and bromides reacted the same way. When $\alpha$-chloro-2-phenylacetyl chloride was used instead, ketene formation only occurred when a heated zinc column with freshly prepared activated zinc was used. However, it was difficult to achieve reliable and stable ketene formation.

To compare the reaction with a classical batch-mode reaction, the reaction was also studied in one pot. Thus, zinc and benzylideneaniline were placed in a flask under argon in $\mathrm{Et}_{2} \mathrm{O}$ and the $\alpha$-butyryl bromide (1) $\mathbf{b}$ ) was added slowly. However, after $2 \mathrm{~h}$ stirring at room temperature and complete consumption of starting material, the crude ${ }^{1} \mathrm{H}$ NMR spectrum showed no desired product $\mathbf{6 h}$, and $\mathrm{N}$-phenylbutyramide (7) could be isolated in $67 \%$ as the major product (Scheme 3 ). This clearly demonstrates the advantage of translocation of a reactive species, which can be achieved by using flow chemistry.

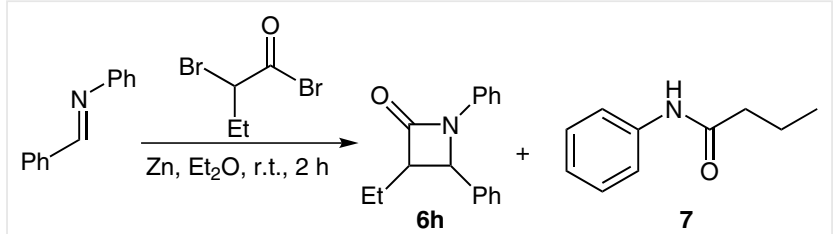

not observed $(67 \%)$

Scheme 3 Test reaction of $\beta$-lactam formation under the same conditions in the batch mode. Isolated yield of $\mathbf{7}$ is given.

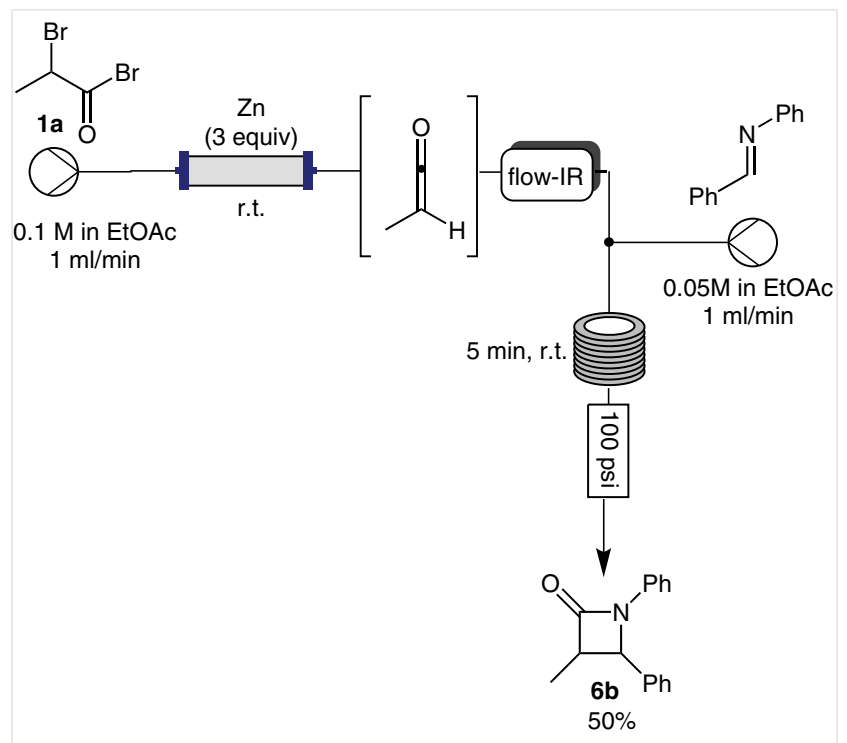

Scheme 4 Synthesis of $\beta$-lactam $\mathbf{6 b}$ by using reactive ketenes in flow. Isolated yield of $\mathbf{6 b}$ is given.
Furthermore, we investigated a full flow protocol for the $[2+2]$ cycloaddition reaction between ketenes and imines. ${ }^{16}$ A stream of generated ketene $\mathbf{2 a}$ was directly reacted inline with a stream of benzylideneaniline. However, because pumping of different streams of low-boiling solvent is challenging, the solvent system was switched. Optimum results were obtained by using ethyl acetate as the solvent. Here, the desired $\beta$-lactam $\mathbf{6 b}$ could be obtained in $50 \%$ yield after a residence time of just 5 minutes (Scheme 4).

In conclusion, we report the generation of monoalkyland phenyl ketenes by using a simple dehalogenation procedure under flow conditions. ${ }^{17}$ The generation of these highly reactive species could be followed by using in-line IR analysis, and the ketenes were obtained in high yields, allowing the preparation of different $\beta$-lactams by a [2+2] cycloaddition reaction at room temperature.

\section{Acknowledgment}

We gratefully acknowledge the EPSRC (Award No. EP/K009494/1) for funding (SVL) and the Alexander-von-Humboldt Foundation for a Feodor Lynen Research Fellowship (AH).

\section{Supporting Information}

Supporting information for this article is available online at http://dx.doi.org/10.1055/s-0034-1380679.

\section{References and Notes}

(1) (a) Allen, A. D.; Tidwell, T. T. Chem. Rev. 2013, 113, 7287. (b) Tidwell, T. T. Eur. J. Org. Chem. 2006, 563.

(2) (a) Cossío, F. P.; Arrieta, A.; Sierra, M. A. Acc. Chem. Res. 2008, 41, 925. (b) Pitts, C. R.; Lectka, T. Chem. Rev. 2014, 114, 7930. (c) Mehta, P. D.; Sengar, N. P. S.; Pathak, A. K. Eur. J. Med. Chem. 2010, 45, 5541. (d) Rasik, C. M.; Brown, M. K. J. Am. Chem. Soc. 2013, 135, 1673.

(3) For selected recent examples, see: (a) Lee, S. Y.; Neufeind, S.; Fu, G. C. J. Am. Chem. Soc. 2014, 136, 8899. (b) Zhang, H.-M.; Gao, Z.H.; Ye, S. Org. Lett. 2014, 16, 3079. (c) Chen, S.; Mondal, M.; Ibrahim, A. A.; Wheeler, K. A.; Kerrigan, N. J. J. Org. Chem. 2014, $79,4920$.

(4) For selected recent examples, see: (a) Ibrahim, A. A.; Nalla, D.; Van Raaphorst, M.; Kerrigan, N. J. J. Am. Chem. Soc. 2012, 134, 2942. (b) Paull, D. H.; Scerba, M. T.; Alden-Danforth, E.; Widger, L. R.; Lectka, T. J. Am. Chem. Soc. 2008, 130, 17260. (c) Tiseni, P. S.; Peters, R. Angew. Chem. Int. Ed. 2007, 46, 5325. (d) Purohit, V. C.; Richardson, R. D.; Smith, J. W.; Romo, D. J. Org. Chem. 2006, 71,4549 .

(5) (a) Allen, A. D.; Andraos, J.; Tidwell, T. T.; Vukovic, S. J. Org. Chem. 2014, 79, 679. (b) Hafez, A. M.; Taggi, A. E.; Wack, H.; Drury, W. J.; Lectka, T. Org. Lett. 2000, 2, 3963. (c) Hafez, A. M.; Taggi, A. E.; Lectka, T. Chemistry 2002, 8, 4114.

(6) Staudinger, H. Chem. Ber. 1911, 44, 533.

(7) McCarney, C. C.; Ward, R. S. J. Chem. Soc., Perkin Trans. 1 1975, 1600. 
(8) (a) Tran, D. N.; Battilocchio, C.; Lou, S.-B.; Hawkins, J. M.; Ley, S. V. Chem. Sci. 2015, 6, 1120. (b) Roda, N. M.; Tran, D. N.; Battilocchio, C.; Labes, R.; Ingham, R. J.; Hawkins, J. M.; Ley, S. V. Org. Biomol. Chem. 2015, 13, 2550.

(9) For selected recent reviews, see: (a) Wegner, J.; Ceylan, S.; Kirschning, A. Adv. Synth. Catal. 2012, 354, 17. (b) Pastre, J. C.; Browne, D. L.; Ley, S. V. Chem. Soc. Rev. 2013, 42, 8849. (c) Deadman, B. J.; Collins, S. G.; Maguire, A. R. Chem. Eur. J. 2014, 21, 2298.

(10) (a) Hartman, R. L.; McMullen, J. P.; Jensen, K. F. Angew. Chem. Int. Ed. 2011, 50, 7502. (b) Ley, S. V.; Fitzpatrick, D. E.; Ingham, R. J.; Myers, R. M. Angew. Chem. Int. Ed. 2015, 54, 3449. (c) Newton, S.; Carter, C. F.; Pearson, C. M.; de C Alves, L.; Lange, H.; Thansandote, P.; Ley, S. V. Angew. Chem. Int. Ed. 2014, 53, 4915. (d) Nalivela, K. S.; Tilley, M.; McGuire, M. A.; Organ, M. G. Chem. Eur. J. 2014, 20, 6603.

(11) Alonso, N.; Miller, L. Z.; de M Muñoz, J.; Alcázar, J.; McQuade, D. T. Adv. Synth. Catal. 2014, 356, 3737.

(12) Glass beads $(<106 \mu \mathrm{m})$ are commercially available from https://www.sigmaaldrich.com.

(13) (a) Cossio, F. P.; Arrieta, A.; Sierra, M. A. Acc. Chem. Res. 2008, 41, 925. (b) Georg, G. I.; Ravikumar, V. T. In The Organic Chemistry of $\beta$-Lactams; Georg, G. I., Ed.; VCH: New York, 1993. (c) Li, B.; Wang, Y.; Du, D.-M.; Xu, J. J. Org. Chem. 2007, 72, 990.

(14) Moore, H. W.; Hughes, G.; Srinivasachar, K.; Fernandez, M.; Nguyen, N. V.; Schoon, D.; Tranne, A. J. Org. Chem. 1985, 50, 4231.

(15) Jiao, L.; Liang, Y.; Xu, J.J. Am. Chem. Soc. 2006, 128, 6060.

(16) During the preparations of this manuscript another ketene reaction in-flow was reported, see: Henry, C.; Bolien, D.; Ibanescu, B.; Bloodworth, S.; Harrowven, D. C.; Zhang, X.; Craven, A.; Sneddon, H. F.; Whitby, R. J. Eur. J. Org. Chem. 2015, 1491; However, the generation of ketenes was performed in situ, in the presence of another reactant.
(17) In-flow generation of ketenes; General procedure:A solution of $\alpha$-bromo acyl halide $(0.05 \mathrm{M})$ in $\mathrm{Et}_{2} \mathrm{O}$ was passed through an Omnifit (http://www.omnifit.com/) glass column, loaded with a mixture of activated zinc $(500 \mathrm{mg})$ and glass beads $(1.0 \mathrm{~g})$ using a Vapourtec R2 platform (http://www.vapourtec.co.uk/ products/rseriessystem). The column output was monitored by using a Mettler Toledo Flow-IR device (http://uk.mt.com/gb/en/ home/products/L1_Autochem Products/ReactIR/flow-irchemis.html). When freshly activated zinc was used, the formation of the corresponding ketene could be observed directly in the IR spectra. When the zinc was not sufficiently activated, ketene formation sometimes did not occur directly. However, the formation could be easily initiated by heating the zinc column for a few seconds. Once the reaction was initiated, ketene formation was stable for about $30 \mathrm{~min}$. CAUTION: Although the work was conducted using low ketene concentrations, special precautions must be taken because ketenes are highly toxic. All work was carried out in a fumehood and the outcoming ketene stream was directly quenched by either the respective coupling partner or a $\mathrm{NaOH}$ solution.

Synthesis of $\boldsymbol{\beta}$-lactams; General procedure: The respective imine $(0.20 \mathrm{mmol})$ was dissolved in $\mathrm{Et}_{2} \mathrm{O}(1 \mathrm{~mL})$ in a vial. The ketene was synthesised according to the in-flow general procedure and an aliquot of the outcoming ketene stream $(0.05 \mathrm{M}, 6$ $\mathrm{mL}, 3 \mathrm{mmol}, 1.5$ equiv) was directly added to the imine solution. The mixture was stirred for another $4 \mathrm{~min}$ and then the reaction was quenched by adding sat. $\mathrm{K}_{2} \mathrm{CO}_{3}(5 \mathrm{~mL})$ and the mixture was stirred for another $5 \mathrm{~min}$. The organic phase was separated and the aqueous phase was extracted with $\mathrm{Et}_{2} \mathrm{O}$. The combined organic phases were dried over $\mathrm{MgSO}_{4}$ and the solvent was removed under reduced pressure. The crude product was purified by flash column chromatography. 